\title{
A IDEOLOGIA NEOLIBERAL: UM ESTUDO SOBRE O NEOLIBERALISMO BRASILEIRO A PARTIR DAS ANÁLISES DE IDADE E RENDA NA ELEIÇÃO DE 2002
}

\author{
THE NEOLIBERAL IDEOLOGY: A STUDY ON BRAZILIAN NEOLIBERALISM FROM \\ ANALYSIS OF AGE AND INCOME IN THE ELECTION OF 2002
}

\begin{abstract}
RESUMO
Nesse trabalho analisamos o pensamento político e econômico da população brasileira nas eleições realizadas no ano de 2002. Essa etapa foi um importante período de transição na nossa política, com a vitória do ex-presidente Lula nas eleições daquele ano, o Brasil passou de um modelo econômico neoliberal ortodoxo, com o Fernando Henrique Cardoso, para um modelo mais à esquerda, de distribuição de renda para algumas camadas sociais. Para dar sentido à proposta do trabalho e ao objeto de pesquisa, contextualizamos a ideologia política do período histórico estudado, tanto no aspecto mundial, quanto nacional. Usamos como referencial teórico principalmente as ideias de Perry Anderson (1995), para tratar do conceito de neoliberalismo, e Althusser (1969) para o conceito de neoliberalismo enquanto ideologia e Armando Boito Junior para essa ideologia no contexto brasileiro. Para a análise, utilizamos como variáveis independentes a idade e a renda dos entrevistados, e cruzamos com intenção de voto do entrevistado para presidente. Também consideramos questões socioeconômicas, como previdência social e impostos, levando em conta a propaganda midiática realizada no período pelos governos e os meios de comunicação, bem como a utilização de exemplos políticos, econômicos e ideológicos mundiais ocorridos durante as últimas décadas do século XX. Concluímos que esses acontecimentos tiveram influência significativa sobre a população brasileira, considerando principalmente os jovens e a classe média.
\end{abstract}

Palavras-chave: neoliberalismo; ideologia; idade; renda.

\begin{abstract}
In this paper, we analyze the political and economic thinking of the Brazilian population in 2002. An important transition period in our politics, with the victory of former President Lula in that year's elections, going to from a neoliberal model with Fernando Henrique Cardoso to a more left-wing model of class reconciliation. In order to give meaning to the work proposal and the object of research, we contextualize the political ideology of the historical period, both in the world and in the national aspect. We use as theoretical reference mainly ideas of Perry Anderson (1995), to treat the concept of neoliberalism, and Althusser (1969) for the concept of neoliberalism and ideology. For the
\end{abstract}


analysis, we used as independent variables with age and the income of the interviewees, and we cross with the intention of the interviewee to vote for president, and socioeconomic issues, such as social security and taxes. Taking into account the media propaganda of the time and the political and economic world that Brazil had during the last decades of the twentieth century, we will understand if these events had a significant influence on the Brazilian population, considering mainly determinate about the young and the middle class.

Keywords: neoliberalism; ideology; ages; income.

\section{INTRODUÇÃO}

As ideias do liberalismo econômico ganham grande adesão no decorrer do século XIX com o economista Adam Smith, um defensor da liberdade econômica como geradora e produtora de mais riqueza. Seu pensamento é hegemônico na maioria dos países europeus até a Revolução Russa de 1917. Após isso, a crise ocasionada a partir da Primeira Guerra Mundial somado a queda da bolsa de valores, em 1929, são marcos importante para um declínio de seus ideais econômicos.

Após a II Guerra Mundial, o Estado de "Bem-Estar Social" europeu passou a ser o modelo de capitalismo em todo o mundo. Isso foi devido à alta movimentação do operariado europeu. A burguesia utilizou os direitos sociais para conter o avanço dos Partidos Comunistas e Socialistas na Europa.

Contudo, após as crises do petróleo nos anos 1970 e o aumento da taxa de juros estadunidense, a emergência das ideias neoliberais nas universidades somado à derrota da esquerda na Inglaterra e nos Estados Unidos, o Welfare State de alguns países europeus deixa de ser o modelo do ideário capitalista e passam a ser seguidas às políticas de ajuste estrutural, diminuindo gastos para áreas sociais. $\mathrm{O}$ exemplo do avanço ideológico neoliberal no período são as premiações concedidas para Hayek em 1974 e Friedman em 1976, no qual ambos autores conquistaram o prêmio do Banco Nacional da Suécia, o Sveriges Riksbank, conhecido como o Prêmio Nobel de Economia.

Como transformação no político ocorre a subida ao poder em 1979; de Margaret Thatcher, Primeira Ministra na Inglaterra, mostrando o avanço do neoliberalismo em um país com forte presença da esquerda. Dentre suas medidas Thatcher desarticulou os sindicatos, recusando a negociação na greve dos mineiros realizada no ano de 1983 e 1984.

Resumindo, em nossa visão, o neoliberalismo é um fenômeno político, econômico e ideológico. Além disso, ao estudar o neoliberalismo concordamos com as ressalvas feitas por Martuscelli (2013) e Nogara; Oliveira (2017), apontando o neoliberalismo como um fenômeno incapaz de ser compreendido mera- 
mente pelos posicionamentos doutrinários de seus ideólogos, pois uma grande ênfase neste aspecto resultaria em uma visão meramente voluntarista desse modelo econômico.

Os governos neoliberais se alastram por todos os continentes, resumidamente, Perry Anderson analisa o que fizeram quando chegaram ao poder: “[...] aboliram controles sobre os fluxos financeiros, criaram níveis de desemprego massivos, aplastaram greves, impuseram uma nova legislação anti-sindical e cortaram gastos sociais" (ANDERSON, 1995. p.11).

Após a queda da União das Repúblicas Socialistas Soviéticas (URSS), a política neoliberal, em um primeiro momento, encontrou-se livre de uma grande concorrência, com isso avançou buscando novos mercados na periferia do capitalismo.

No Brasil, a presença do Estado na economia é forte desde a década de 1930 após a Revolução de 30 que pôs fim a antiga ordem oligárquica da Primeira República. Na ditadura militar brasileira permaneceu essa prática de forte presença estatal, com o país permanecendo sob alta estatização em determinados setores da econômica como petróleo, água, mineração, setor bancário, etc. No entanto, após crise da ditadura brasileira em meados da década de 1980, bem como a crise do Estado desenvolvimentista em todo o planeta nesse período, as ideias neoliberais passam a ganhar força no Brasil. É nesse contexto que ocorre a chegada do neoliberalismo no país.

Um dos aspectos da eleição de Fernando Collor contra Lula em 1989 é a vitória ideológica do neoliberalismo no país. Collor venceu a disputa pregando uma diminuição do Estado com o lema de "caçador de marajás". Durante sua campanha e inclusive nos debates políticos ocorreram diversas manipulações produzidas pelos meios de comunicação para, no plano ideológico, aludir as massas sobre os benefícios da entrada do país nesse novo sistema econômico neoliberal (BOITO JUNIOR, 1996). Através disso convenceu diversos setores da população devido ao grande apoio empresarial e midiático da sua candidatura para barrar Lula. Em seu governo, existiram propagandas oficiais, comparando o Estado a um elefante lento, pesado e que não acompanhava o processo "mundial" de corrida.

Collor antes de sua deposição elaborou o PND (Plano Nacional de Desestatização), fitando a privatização das estatais, mostrando sua aptidão ao adotar uma das prerrogativas dos governos neoliberais. Collor não obteve êxito em seu governo, sendo deposto através de um processo de impeachment em 1992, o presidente foi substituído por seu vice, Itamar Franco.

A frase Caçador de Marajás se referia ao combate dos funcionários públicos ociosos, segundo opinião do candidato, realizados na vigência do seu mandato como governador do Estado de Alagoas entre 1987 e 1989. 
O PND seguiu no governo FHC, com a mudança de nomenclatura para CND (Conselho Nacional de Desestatização), no entanto, o caráter privatizante do programa permaneceu o mesmo de quando fora implementado por Collor (CASTRO SILVEIRA, 2009).

Importante lembrar que as "reformas" neoliberais foram realizadas com uma alusão técnicas de melhoria das funções do mercado em relação ao Estado. Nesses aspectos supostamente técnicos, estava em jogo a diminuição do poder dos sindicatos, afinal os trabalhadores sindicalizados seriam uma obstrução as políticas de privatizações e desregulamentação no trabalho (GALVÃO, 2003).

Dentre todos os fatores citados, o trabalho tem como problemática o pensamento do brasileiro sobre a presença do Estado em seu cotidiano. O banco de dados utilizado nas tabelas foi o da Pesquisa Social Brasileira (PESB) do ano de 2002 .

O estudo justifica-se pela necessidade de compreensão da adesão do neoliberalismo na sociedade brasileira. Mesmo sendo um estudo de caráter histórico, acreditamos ter implicações práticas no nosso cotidiano, afinal os elementos neoliberais continuam presente na formação social brasileira.

Para tratar do conceito de neoliberalismo, serão utilizadas as ideias de Perry Anderson (1995). Na definição desse autor, o neoliberalismo quer um Estado forte, mas para reprimir parcelas pobres da população. Somente nas questões de assistência social esse Estado deve ser o menor possível.

Em relação ao conceito do neoliberalismo enquanto ideologia, usaremos a definição de Althusser (1969). O autor apresenta a ideologia como material e inconsciente, servindo para manter os sujeitos subordinados em determinada condição social. A ideologia é material por se manifestar nos "Aparelhos Ideológicos do Estado", tais como a escola e a mídia.

Trabalhamos com a hipótese de determinadas camadas sociais de idade e renda possuírem um pensamento favorável ao neoliberalismo devido à propaganda positiva em detrimento desse sistema econômico realizado nos aparelhos ideológicos².

A justificativa para tal hipótese se dá pelo fato de, nos anos 90 ocorrerem diversas propagandas críticas ao Estado, essas manifestações partiam tanto de

\footnotetext{
Assim como Althusser, entendemos os aparelhos ideológicos como:

O AIE religioso (o sistema das diferentes Igrejas),

O AIE escolar (o sistema das diferentes escolas públicas e particulares),

O AIE familiar,

O AIE jurídico,

O AIE político (o sistema político de que fazem parte os diferentes partidos),

O AIE sindical,

O AIE da informação (imprensa, rádio-televisão, etc.

O AIE,cultural (Letras, Belas Artes, desportos, etc.). (ALTHUSSER, 1969, p. 43-44, grifo nosso).
} 
integrantes do parlamento reacionário da época ${ }^{3}$ e também dos meios de comunicação.

A variável idade justifica-se pelo fato do neoliberalismo relativamente no país até a data do banco de dados, no ano de 2002 . O neoliberalismo, de fato, atinge o país com a chegada de Collor ao poder em 1989, somente a partir daí as ideias neoliberais adentram os aparelhos ideológicos de forma hegemônica. Quem vivenciou esse caráter do Estado neoliberal não possui mais de 30 anos, ou seja, ainda está na juventude.

Renda é outra variável importante para o estudo. A classe média e a burguesia brasileira não possuem um projeto nacional de país ${ }^{4}$. Diante disso, percebe-se a falta de reformas estruturais básicas tais como reforma agrária, educação pública de qualidade e mudanças no sistema de taxação de impostos. A classe média brasileira, no geral atua como classe de apoio para a burguesia, pois reforça o discurso ideológico neoliberal criticando os gastos sociais do governo.

A renda foi definida em dois grupos, alta e baixa. A renda baixa agrupa as famílias com renda menor que 4 mil reais. Se usou esse método pelo fato do salário mínimo estipulado pelo Departamento Intersindical de Estatística e Estudos Socioeconômicos (DIEESE) em 2002 ser de R\$1,143,00. Soma-se a isso o fato da família brasileira possuir em 2002 a média de 3,3 pessoas. A definição de renda alta de fato foi estipulada por quem ultrapassa o valor mínimo estipulado pelo Dieese, no caso quem ganha 4 mil reais ou mais.

As variáveis dependentes serão a previdência social, pois é um setor fortemente bombardeado por seus altos custos. A outra variável dependente será representada pelos-candidatos neoliberais da eleição de 2002. De um lado foram agrupados candidatos como José Serra do Partido da Social Democracia Brasileira (PSDB) e Anthony Garotinho do Partido Socialista Brasileiro (PSB), todos esses, aspirantes à presidência com propostas de, no geral, continuação do neoliberalismo de Fernando Henrique Cardoso (FHC), tanto no aspecto política econômica, como no âmbito repressivo as populações pobres. De outro lado estão agrupados candidatos representantes de uma alternativa ao neoliberalismo, além de suas propostas conflitantes com o neoliberalismo, tais candidatos eram apoiados por movimentos sociais e sindicatos contrários ao projeto neoliberal. Esses candidatos são: Lula do Partido dos Trabalhadores (PT), Ciro Gomes do

\footnotetext{
Em grande parte o congresso concordou com as políticas de privatização (ALMEIDA; MOYA, 1997).

Os mandatos que tiveram essa preocupação como o segundo governo Vargas e até coalizões moderadas como Juscelino Kubitschek e João Goulart, não eram representantes oficias da burguesia, possuíam algumas parcelas desses setores em seus governos, mas também foram apoiados por diversas camadas pobres da população (OLIVEIRA, 2018).
} 
Partido Popular Socialista (PPS), Zé Maria do Partido Socialista dos Trabalhadores Unificado (PSTU) e Rui Costa Pimenta do Partido da Causa Operária (PCO).

Devido as várias ambiguidades e transformações dos partidos dentro das formações sociais fica difícil estabelecer um critério geral para descrever direita e esquerda e favoráveis ou desfavoráveis ao neoliberalismo. Para Bobbio (1994) a diferença entre direita e esquerda residiram na questão de desigualdade. A esquerda busca eliminar as desigualdades, já para a direita a desigualdade seria um elemento natural, logo passível de convivência devido sua inevitabilidade. Entretanto, estamos de acordo com SEGRILLO (2004, p. 623-624) no qual a esquerda, especialmente os socialistas e comunistas, busca transformações radicais naquilo que é considerado prejudicial. Já a direita busca a manutenção do status quo. Logo, levamos essa consideração teórica para os âmbitos relacionados a variável neoliberalismo nesse presente trabalho.

Nessa eleição de 2002, os candidatos da esquerda aludiam essa transformação. A direita, de alguma forma, mantinha o status quo, visto que devido à péssima imagem do governo FHC, nenhuma candidatura em seus planos fomentava um governo equivalente aos do PSDB nos últimos dois mandatos

Como última variável estão os impostos, também alvo de imensa propaganda da burguesia, aludindo ser necessária uma diminuição desses encargos para o bem comum de toda formação social.

\section{A IDEOLOGIA}

O autor franco-argelino, Louis Althusser apresentou uma nova problemática para a questão da ideologia contrapondo algumas questões expostas por Marx e Engels na Ideologia Alemã (2007) rejeitando conceitos expostos nessa obra, tais como o de "falsa consciência". Para Althusser, a ideologia não seria somente inconsciente, ela possui uma materialidade. Em seu célebre livro, Ideologia e Aparelhos ideológicos do Estado, Althusser (1969) formula uma teoria geral da ideologia através de uma conceitualização materialista e marxista, sua crítica a Ideologia Alemã de Marx é devido a características hegelianas ainda presentes nesse autor, tais implicações idealistas, segundo Althusser, só "desapareceriam" em obras maduras como O Capital.

Existem quatro concepções da ideologia althusseriana: ela obedece a uma dinâmica inconsciente; possui uma função matricial de coesão social; possui uma materialidade; e interpela os indivíduos como sujeitos (NAVES, 2010, p. 37).

Sobre a primeira tese, Althusser (1969) afirma que a ideologia é uma representação imaginária dos indivíduos com as suas condições de existência. 
A ideologia é uma concepção de mundo, essas concepções são, em grande parte, imaginárias, não correspondendo a realidade. $O$ fato de não ser real, não significa afirmar sua falsidade, a ideologia é real, sua "falsidade" resiste na deformação imaginária do pensamento. Mesmo com essa alteração, as ideologias fazem alusão a alguma realidade. Portanto, a ideologia é uma alusão/ilusão.

A função matricial da ideologia serve para manter os indivíduos sob uma dominação de classe, fazendo os mais explorados aceitarem sua situação. Nesse ponto, a ideologia é superior a subjetividade dos indivíduos, esse processo ocorre através de efeitos estruturais (NAVES, 2010). Nesse ponto, Stuart Hall (2003, p. 172) formula a possibilidade de um funcionalismo em Althusser, devido a não formulação de uma ideologia das classes dominadas, discordamos dessa visão, afinal Althusser não crê na imposição de ideologias por partes das estruturas, a ideologia permeia inclusive as estruturas. É somente a partir da entrada da ideologia nas estruturas que elas passam a atuar, é por isso o chamado do autor às organizações operárias atuarem por fora da estrutura estatal.

$\mathrm{Na}$ tese sobre a materialidade da ideologia, a relação imaginária é, em si mesma, dotada de uma existência material, afinal, a existência das ideias são "atos materiais inseridos em práticas materiais, reguladas por rituais materiais, eles mesmos definidos pelo aparelho ideológico material de onde provêm as ideias do dito sujeito" (ALTHUSSER, 1969, p. 88-89). Em seu texto é exemplificado o sistema material da ideologia como resultado de uma prática seja fala, um gesto, etc.

As ideias desaparecem enquanto tais (enquanto dotadas de uma existência ideal, espiritual), na medida mesma em que se evidenciava que sua existência estava inscrita nos atos das práticas reguladas por rituais definidos em última instância por um aparelho ideológico. O sujeito, portanto atua enquanto agente do seguinte sistema (enunciado em sua ordem de determinação real): a ideologia existente em um aparelho ideológico material, que prescreve práticas materiais regulares por um ritual material, práticas estas que existem nos atos materiais de um sujeito, que age conscientemente segundo sua crença (ALTHUSSER, 1969, p. 90).

A O foco da ideologia não deve ser suas ideias e simbolismos, mas sim suas práticas. Toda ideologia está vinculada a uma prática inscrita em instituições materiais. Aqui reside o ponto chave da teoria althusseriana da ideologia, pelo fato dela estar vinculada a uma prática, sua função é garantir a submissão dos sujeitos, não meramente através da força, e sim, sob o seu aspecto ideológico, por isso a escola tem função essencial nesse papel (NAVES, 2010, p. 48). 
Seu último ponto sobre a ideologia é a interpelação dos indivíduos enquanto sujeitos. A ideologia, em suas formas já citadas, acolhe todos indivíduos o transformando em sujeitos. Esse processo, segundo o franco-argelino, ocorre desde a barriga da mãe, sendo assim, ao nascer, o indivíduo já é um sujeito. (ALTHUSSER, 2010, p. 102). Stuart Hall faz um diálogo com Althusser explicitando a interpelação dos indivíduos como sujeitos citando um caso próprio:

Essa observação me recorda urna experiência de infância semelhante. Trata-se de urna história freqüentemente recontada em minha família sempre motivo de risos, embora eu nunca tenha visto graça nela; faz parte do folclore familiar de quando minha mãe me trouxe do hospital depois que nasci. Minha irmã olhou para o berço e disse: "ande você arranjou esse bebe coolie?" Os coolies na Jamaica são os indianos, descendentes dos trabalhadores trazidos como semi-escravos ao país após a Abolição para substituírem os escravos nas plantações, Coolie denota, se é que é possível, um grau abaixo de "negro" no discurso da raça. Esta foi a forma que minha irmã encontrou de dizer que eu tinha saído bem mais escuro do que a média em nossa família, o que pode acontecer nas melhores famílias miscigenadas. Nem sei mais se isso aconteceu mesmo ou se foi uma história fabricada por minha família ou talvez se fui eu quem a inventou e agora me esqueci quando ou por que. Mas me senti, naquela época como agora, convocado ao meu "lugar" por aquela história. A partir de então, meu lugar nesse sistema de referência tornou-se problemático. Isso pode ajudar a explicar porque e como eu eventualmente me tornei aquilo pelo qual fui norteado pela primeira vez: o coolie de minha família, aquele que não se ajustou, o estrangeiro, aquele que ficava na rua em má companhia e cresceu com aquelas idéias malucas na cabeça[...] (HALL, 2003, p. 190).

A teoria da ideologia de Louis Althusser avança o marxismo, servindo de grande importância para compreender nossa a realidade material do mundo vívido. Sob esse aspecto, desde sua infância, o indivíduo já é interpelado como sujeito, devido às estruturas familiares e sociais. Ao longo da vida do sujeito, ele reproduzirá uma ideologia que, em muitas vezes, será uma alusão a alguma realidade, mesmo assim, ela terá uma existência material devido a reprodução por práticas do sujeito.

Para análise da situação brasileira utilizamos de autores como Boito (2013) no qual afirma que a massa desorganizada apoiou a candidatura de Lula perseguindo aspirações difusas em torno de um melhoramento de suas condições de vida. 


\section{NEOLIBERALISMO}

Em nossa visão, o neoliberalismo é um fenômeno político, econômico e ideológico. No campo político, o neoliberalismo mantém um Estado forte para desarticular o poder dos sindicatos bem como minar o proletariado, entretanto, esse mesmo Estado é reduzido em gastos sociais para a parcela pobre da população (ANDESRON, 1995).

Analisando seus governos, podemos concluir que a política neoliberal é de suprimir as organizações sindicais. Como exemplo, Margaret Thatcher evitou a negociação na greve dos mineiros em 1984. Os mineiros eram um elemento central no sindicalismo britânico, ao final de seu governo a ação sindical caiu em um décimo comparado ao período do governo anterior a Thatcher. Outro exemplo é de Ronald Reagan presidente dos Estados Unidos, no ano de 1981, derrotando a greve dos controladores de voo e desarticulando seu respectivo sindicato (HARVEY, 2008).

Grande amostra das políticas neoliberais é o Consenso de Washington, importante instrumento de difusão do modelo, exportando das economias centrais para a periferia do mundo capitalista, e inclusive de antigos países socialistas, o neoliberalismo enquanto ideologia e suposto modelo de desenvolvimento. O Consenso de Washington foi resultado de uma série de debates e encontros ocorridos na capital estadunidense com amplo apoio de instituições como o FMI (Fundo Monetário Internacional), a OMC (Organização Mundial do Comércio) e o Banco mundial. Tal "consenso" publicou documentos no ano de 1990, elencando uma espécie de "manual do desenvolvimento" para os países seguirem, sendo recomendado e respaldado internacionalmente pelos imperialismos ${ }^{5}$.

Em Junho de 2016, diretores do FMI lançaram um documento criticando suas próprias políticas neoliberais, afirmando ter fracasso no combate à desigualdade social no mundo (OSTRY; LOUNGANI; FURCERI, 2016).

No campo econômico, temos como marco dos ditames, o aumento inflacionário, em 1979, de Paul Volcker, chefe do Banco Central dos Estado Unidos na época, causador de grande crescimento da dívida pública de países subdesenvolvidos. México em 1982 e Brasil no ano de 1987, devido esse fator, ambos países, tiveram de decretar moratória momentânea.

Na prática, não podemos designar neoliberalismo como um modelo de crescimento econômico, isso é uma alusão proclamada por alguns de seus ideólogos. Sua taxa de crescimento é menor em comparação as décadas anteriores

5 Compreendemos o imperialismo como a fusão dos capitais bancário e industrial, que unidos formam associações internacionais dividindo entre si sua esfera de atuação (LÊENIN, 1985). 
a II Guerra Mundial. Além de que, quem leva os ganhos dessa política são os Estado Unidos, mesmo nos grandes países da Europa, a taxa de crescimento caiu absurdamente. (DUMÉNIL; LÉVY, 2004, p. 16).

A economia neoliberal pode ser resumida em 5 pontos: 1 - a divisão entre mercados e Estado colocando-os como rivais; 2 - Imposição da ideia de maior eficiência dos mercados em relação ao Estado; 3 - Globalização financeira; 4 A estabilidade econômica advinda através de baixa inflação; 5 - Garantias ilimitadas ao sistema financeiro (SAAD FILHO, 2015, p.62).

Por fim, no campo ideológico, as ideias neoliberais são de um livre mercado, fomentando capacidades empreendedoras individuais. Para os neoliberais, a liberdade individual só poderá ser garantida concomitantemente com liberdade de mercado e comércio. O marco do ideário neoliberal é a Sociedade Mont Pélerin, faziam parte dessa associação, teóricos como Ludwig von Mises, Friedrich Hayek, Walter Lipmann, Karl Popper e Milton Friedman. Os neoliberais ganham prestígio, de fato, após vencerem, o prêmio Sveriges Riksbank (HARVEY, 2005).

A Sociedade Mont Pélerin obteve apoio financeiro dos Estados Unidos e de líderes corporativos. Seus membros, receosos com a ameaça comunista, aceitavam praticamente qualquer ideia contrária a esse ideário, contudo, tais intelectuais, até a década de 1970, eram inexpressivos. A partir do reconhecimento ao ganharem o Sveriges Riksbank (que estava sob controle da elite bancária Suíça nas vitórias de Friedman e Hayek) as ideias neoliberais passam a entrar na academia, de início, na Universidade de Chicago a logo após se espalhando globalmente. (HARVEY, 2005)

No Brasil, o neoliberalismo concretiza-se, de fato, após a subida de Collor ao poder em 1990, permanecendo até a atualidade. Todos esses governos, de Fernando Collor à Michel Temer, mantiveram o tripé macroeconômico neoliberal, realizando uma política econômica de juros altos, superávit primário e câmbio desvalorizado (BOITO JR, 2003).

O neoliberalismo ainda é hegemônico mundialmente. Instituições como FMI permanecem com grande influência no pensamento econômico, e governos, em quase sua totalidade, tentam ao máximo desarticular o movimento sindical.

No campo ideológico, após a crise de 2008, as teorias neoliberais vêm sofrendo inúmeras críticas, mesmo assim, possuem grande presença nos Aparelhos Ideológicos do Estado. A ideologia neoliberal não foge do esquema teórico da ideologia althusseriana. O ideário das políticas neoliberais impõe práticas aos países emergentes e subdesenvolvidos. A exigência varia desde o aumento 
de juros por parte dos países imperialistas em determinados momentos até uma realização de ajuste estrutural permanente por parte dos países atrasados, tal ideia materializa-se por parte das instituições como FMI interpelando os sujeitos fazendo alusão dessa ser a única possibilidade de sair da crise, ou de alavancar o país para o rol dos desenvolvidos.

\section{ANÁLISE DA ACEITAÇÃO DAS IDEIAS NEOLIBERAIS NO BRASIL}

Tabela 1 - opinião sobre a previdência social

\begin{tabular}{|c|c|c|c|c|c|}
\hline \multirow{2}{*}{\multicolumn{2}{|c|}{ Tabela 1}} & \multicolumn{3}{|c|}{$\begin{array}{l}\text { Opinião sobre quem deve administrar a aposen- } \\
\text { tadoria e previdência social }\end{array}$} & \multirow{3}{*}{$\begin{array}{l}\text { Total } \\
28,5 \%\end{array}$} \\
\hline & & Governo & $\begin{array}{l}\text { Governo e empre- } \\
\text { sas particulares }\end{array}$ & $\begin{array}{l}\text { Empresas parti- } \\
\text { culares }\end{array}$ & \\
\hline \multirow[b]{2}{*}{ Idade } & Jovens & $27,7 \%$ & $25,5 \%$ & $35,8 \%$ & \\
\hline & $\begin{array}{l}\text { Adultos e } \\
\text { idosos }\end{array}$ & $72,3 \%$ & $74,5 \%$ & $64,2 \%$ & $71,5 \%$ \\
\hline \multicolumn{2}{|l|}{ Total } & $100 \%$ & $100 \%$ & $100 \%$ & $100 \%$ \\
\hline \multicolumn{4}{|c|}{ Fonte: (PESB, 2002) } & $\mathrm{p}<0,05$ & \\
\hline
\end{tabular}

A previdência social é um gasto corrente nas contas públicas estatais, sendo assim seu peso no orçamento é propagandeado como maléfico desde a chegada do neoliberalismo no Brasil. Com a forte propaganda neoliberal alegando uma necessidade de redução das funções sociais do Estado, a população mais jovem passou a ser atraída por esse pensamento em relação a suposta alta oneração do orçamento público, e, mesmo tendo de contribuir para sua aposentadoria, prefere, em sua relativa maioria, que o ente privado assuma as responsabilidades em gerir a aposentadoria.

A ideologia neoliberal, devido sua forte pressão em relação a redução do poder do Estado nas questões sociais, tem facilidade em alcançar pessoas com renda mais alta, principalmente por não sentirem-se necessitadas da presença estatal (conforme veremos na Tabela 2). Dessa forma, ao se descaracterizarem como beneficiários do Estado, reafirmam a sua disposição ideológica de retração dos direitos sociais, em detrimento de uma economia privada contrária a esse aspecto econômico. 
Tabela 2-Opinião sobre aposentadoria

\begin{tabular}{|c|c|c|c|c|c|}
\hline \multirow{2}{*}{\multicolumn{2}{|c|}{ Tabela 2}} & \multicolumn{3}{|c|}{$\begin{array}{c}\text { Opinião sobre quem deve administrar a aposenta- } \\
\text { doria } \\
\text { e previdência social }\end{array}$} & \multirow[t]{2}{*}{ Total } \\
\hline & & Governo & $\begin{array}{c}\text { Governo e empresas } \\
\text { particulares }\end{array}$ & $\begin{array}{l}\text { Empresas parti- } \\
\text { culares }\end{array}$ & \\
\hline \multirow{2}{*}{ Renda } & $\begin{array}{l}\text { Baixa } \\
\text { renda }\end{array}$ & $95,6 \%$ & $92,4 \%$ & $93,1 \%$ & $94,8 \%$ \\
\hline & $\begin{array}{l}\text { Alta } \\
\text { renda }\end{array}$ & $4,4 \%$ & $7,6 \%$ & $6,9 \%$ & $5,2 \%$ \\
\hline \multicolumn{2}{|l|}{ Total } & $100 \%$ & $100 \%$ & $100 \%$ & $100 \%$ \\
\hline & & & $\mathrm{p}<0,05)$ & \\
\hline
\end{tabular}

Com essas razões, conseguimos passar a compreensão de que, para a burguesia, os indivíduos pertencentes a famílias com renda alta, a presença do Estado é, sobretudo, um peso financeiro. Pois, sentem-se como contribuintes apenas, não como beneficiários do poder estatal.

Dezoito milhões de pessoas recebem seu sustento sob a forma de aposentadorias e pensões do Instituto Nacional de Seguridade Social (INSS). No setor público, há aproximadamente três milhões de aposentados e pensionistas que, considerando os três poderes, recebem em média 14 SM. O contraste é significativo. Se tomarmos separadamente as aposentadorias dos três poderes, veremos que aquela média mascara outras discrepâncias. No Executivo federal há cerca de 900.000 inativos com benefícios médios em torno de 4,5 SM; esta média sobe para 34,7 SM no Judiciário e para 36,8 SM no Legislativo. Este quadro de desigualdade de condições de aposentadoria, que vem sendo explorado pelos governos neoliberais, é histórico e objetivo. Ele cria uma base material para a revolta popular contra os funcionários públicos, supostamente "privilegiados" e responsáveis pelas agruras do setor privado e de seus trabalhadores (BOITO JR, 2000, p. 198).

O Plano Real foi um fracasso6 em alguns aspectos, devido ao aumento da dívida e os três empréstimos do país (1998, 2001 e 2002) designados ao FMI, sendo o empréstimo de 2002, o maior pedido de empréstimo ao FMI até essa data7. Segundo Sallum (2000) no plano econômico, Fernando Henrique Cardoso

6 Theotônio dos Santos (2010) em Carta Aberta ao ex-presidente Fernando Henrique afirma que o Plano Real não acabou com a alta inflação brasileira, pois todas as economias durante a década de 1990 tiveram uma deflação de no mínimo 10\%. A inflação brasileira segundo o autor continuou uma das maiores do mundo. Além disso, o Plano Real elevou a dívida pública brasileira.

7 O empréstimo realizado foi no valor de 30 bilhões de dólares. 
não conseguiu equilibrar as contas públicas, pois o neoliberalismo dominou a política cambial e monetária da época, somado ao baixo crescimento e desnacionalização da economia.

Desde Collor há um aumento das privatizações no país abrindo o país para o comércio estrangeiro, iniciando a reestruturação produtiva nas empresas (OLIVEIRA, 2018). Com FHC há um novo impulso de mudanças no parque industrial com o fechamento de empresas nacionais devido à alta valorização do real, queda no nível de emprego, bem como uma desnacionalização da econômica (DINIZ, 2010, p. 107).

Tabela 3 - Intenção de votos de jovens e adultos

\begin{tabular}{|c|c|c|c|c|}
\hline \multicolumn{2}{|c|}{ Tabela 3} & \multicolumn{2}{|c|}{ Intenção de voto em candidatos neoliberais } & \multirow{3}{*}{$\begin{array}{c}\text { Total } \\
30,0 \%\end{array}$} \\
\hline & & $\operatorname{Sim}$ & Não & \\
\hline \multirow[t]{2}{*}{ Idade } & Jovens & $33,0 \%$ & $28,4 \%$ & \\
\hline & Adultos e idosos & $67,0 \%$ & $71,6 \%$ & $70,0 \%$ \\
\hline \multicolumn{2}{|l|}{ Total } & $100 \%$ & $100 \%$ & $100 \%$ \\
\hline \multicolumn{3}{|c|}{ Fonte: (PESB, 2002) } & $\mathrm{p}<0,05$ & \\
\hline
\end{tabular}

Mesmo diante de tal revés econômico, a juventude brasileira apostou na continuidade desse projeto, conforme demonstrado na Tabela 3. Nessa eleição, os candidatos Lula e Ciro Gomes, em 2002 enfatizavam a necessidade da volta de um Estado forte em suas propagandas eleitorais. O candidato do Partido dos Trabalhadores, embora em tom mais moderado em comparação a eleições anteriores como a sua primeira eleição em 1989, seguia com um caráter crítico as privatizações feitas no período neoliberal de FHC. Outras candidaturas, como Zé Maria do PSTU e Rui Costa Pimenta do PCO avançavam nesse aspecto em relação a Ciro Gomes e Lula, incluindo em seus programas de governo a reestatização de empresas privatizadas na era FHC.

A gama de candidatos de esquerda é um reflexo do difundido fracasso da política neoliberal implementada pelo PSDB, tal crítica partia inclusive de setores do próprio empresariado. Um exemplo de união de interesses entre o partido de esquerda e parte da burguesia insatisfeita foi à aliança do Partido Liberal $(\mathrm{PL})$ postulando o nome do então dono da Coteminas, um grande grupo têxtil brasileiro, José de Alencar para ser vice de Lula (DINIZ, 2010, p. 117-118). A partir de então forma-se uma frente neodesenvolvimentista no qual o PT já alude que beneficiará um setor da burguesia, como esse comandado por José Alencar, possuindo diferenças com o governo do PSBD que privilegiava um setor da burguesia com maiores ligações com o capital estrangeiro (BOITO JUNIOR, 2013) 
Althusser (1969) aponta que a ideologia interpela indivíduos enquanto sujeitos em uma formação social de classes e serve para manter tais sujeitos em determinada situação social. A juventude votou Serra por acreditar na necessidade do avanço do projeto neoliberal. A propaganda neoliberal nunca demonstrou tal projeto como uma etapa selvagem do liberalismo, e sim, como um avanço de prosperidade.

Após a queda da URSS o paradigma neoliberal virou predominante no mundo, mesmo com arrocho salarial, desmonte do Estado nacional e desemprego, a imensa propaganda da alta inflação, da imagem salvadora do Plano Real estão presentes na memória da juventude nesse momento da pesquisa.

Tabela 4- Posicionamento sobre impostos

\begin{tabular}{l|l|c|c|c}
\hline \multirow{2}{*}{ Tabela 4 } & \multicolumn{2}{|c|}{ Posição sobre não pagar impostos } & \multirow{2}{*}{ Total } \\
\cline { 3 - 4 } \multicolumn{2}{l|}{} & Depende da situação & Sempre errado & \\
\hline \multirow{2}{*}{ Idade } & Jovens & $35,2 \%$ & $24,3 \%$ & $28,5 \%$ \\
\cline { 2 - 5 } & Adultos e idosos & $64,8 \%$ & $75,7 \%$ & $71,5 \%$ \\
\hline \multicolumn{2}{|l|}{ Total } & $100 \%$ & $100 \%$ & $100 \%$ \\
\hline (Fonte: PESB, 2002) & \multicolumn{2}{|c}{$\mathrm{p}<0,05$} &
\end{tabular}

$\mathrm{N}=2335$

Na visão da burguesia, o Brasil tem elevadas taxas de impostos, a propaganda sobre isso é alta, chegou-se ao caso de conjuntos empresariais como a Associação Comercial de São Paulo criar um impostômetro para medir a totalidade de impostos pagos pelos brasileiros. Devido a imensa propaganda, tornou-se senso comum do brasileiro acreditar na necessidade da redução de impostos. Tal imposição ideológica é um dos aportes do neoliberalismo, pois a redução de impostos beneficia em muito o setor empresarial, aumentando seus lucros, bem como diminuído a arrecadação financeira do Estado, culminando no esfacelamento de serviços públicos (BOITO JUNIOR, 1999).

Essa determinação ideológica da burguesia é recente, ela convence o jovem com baixo salário com o discurso favorável à redução de impostos, afinal, pela taxação dos impostos brasileira ser regressiva, é a parcela com renda baixa da população quem paga mais paga impostos. No entanto a burguesia brasileira segue fazendo uma propaganda de alusão ao real, fornecida em termos de ilusão:

Era justamente até aqui que tínhamos de remontar para compreender porque a ideologia como representação do mundo e da sociedade, é necessariamente uma representação deformante e mistificadora da realidade em que os homens tem de viver uma representação destinada 
a faze-los aceitar em sua consciência e em seu comportamento imediatos, o lugar e o papel de que lhes impõe a estrutura desta sociedade. Agora é possível compreender porque a ideologia dá a realidade uma certa "representação", porque ela faz de certa maneira alusão ao real, mas porque ao mesmo tempo ela não oferece sobre o real mais do que uma ilusão. A ideologia dá aos homens certo "conhecimento" de seu mundo - ou melhor, permitindo-lhes "reconhecerem-se" em seu mundo, dá aos homens um certo "reconhecimento" - mas ao mesmo tempo não os introduz senão em seu desconhecimento. Alusão - ilusão ou reconhecimento - desconhecimento: assim é a ideologia do ponto de vista de sua relação com o real. (ALTHUSSER, 1967. p. 40, grifos do autor).

\section{CONSIDERAÇÕES FINAIS}

Levando em consideração as variáveis cruzadas, percebemos que tanto idade como renda dos sujeitos são fundamentais para compreender o pensamento do brasileiro sobre a presença do Estado em seu cotidiano.

Os jovens herdeiros da carga ideológica neoliberal, através da política vigente, tanto no plano nacional, como mundial, incorporaram em seu pensamento o neoliberalismo, ideologia dominante da época. Devido esse suporte do ideário neoliberal de Estado mínimo, os jovens defendem uma grande presença de instituições privadas para controlar a previdência social, sendo favoráveis, inclusive, a renúncia do pagamento de impostos em determinadas situações. Observamos o reflexo desses pensamentos na intenção de voto desses jovens, afinal, a maioria desse grupo apresentou desejo em votar nos candidatos neoliberais.

O artigo também apresentou a pertinência do caráter renda, pois a classe média e a burguesia se apoiam mutuamente no seu anti-projeto nacional, para isso fomentam propagandas, alegando um mau funcionamento do Estado, a disseminação desse ideário anti-estatal tem como função destruir a imagem dos órgãos nacionais.

O artigo possui relevância para compreender o caráter ideológico das parcelas sociais do Brasil. Soma-se a isso, a falta de estudos quantitativos sobre o caráter ideológico da juventude brasileira, mesmo a pesquisa enfatizando em um momento histórico do país, entendemos ser de grande pertinência para a comunidade acadêmica.

A partir dos resultados desse trabalho é possível ter um maior entendimento dessas frações sociais da formação histórico-social brasileira, além da presença hegemônica do pensamento neoliberal. 


\section{REFERÊNCIAS}

ALMEIDA, Maria; MOYA, Mauricio. A reforma negociada: o Congresso Nacional e a política de privatizações. Revista Brasileira de Ciências Sociais, São Paulo, v. 12, n.34, p. 119-132, 1997.

ALTHUSSER, Louis. Ideologia e aparelhos ideológicos do Estado. 1. ed. Lisboa: Presença, 1969.

ALTHUSSER, Louis. Marxismo segundo Althusser. São Paulo: Sinal, 1967.

ALVES, Giovani. Trabalho e Sindicalismo no Brasil: Um balanço crítico da década neoliberal (1990-2000). Revista de Sociologia e Política, Curitiba, v. 19, p. 71-94, 2002.

ANDERSON, Perry. "Balanço do neoliberalismo”. In: SADER, Emir e GENTILI, Pablo. (orgs.) Pós Neoliberalismo - as políticas sociais e o Estado democrático. Rio de Janeiro: Paz e Terra, 1995, p.9-38.

BOBBIO, Norberto. (1994), Destra e Sinistra: Ragioni i Significati di una Distinzione Politi-ca. Roma, Donzelli.

BOITO JR., Armando. Política neoliberal e sindicalismo no Brasil. São Paulo: Xamã, 1999.

BOITO JUNIOR, Armando. A hegemonia neoliberal no governo Lula. Crítica Marxista (São Paulo), Rio de Janeiro, v. 17, p. 9-35, 2003.

BOITO JUNIOR, Armando. Neoliberalismo e lutas sociais no Brasil. Campinas, 2003.

BOITO JUNIOR. Armando. O lulismo é um tipo de bonapartismo? Uma crítica às teses de André Singer. Critica Marxista (São Paulo), v. 37, p. 171-181, 2013.

BOITO JUNIOR. Hegemonia neoliberal e sindicalismo no Brasil. Crítica Marxista (São Paulo), SÃO PAULO, v. 3, p. 80-104, 1996.

CASTRO SILVEIRA, Ramaís. Neoliberalismo: Conceito e influências no Brasil De Sarney a FHC. 2009, 176 f. Dissertação (mestrado em ciência política) - UFRGS, Porto Alegre, 20 de março de 2009.

DINIZ, Eli. Empresariado Industrial, representação de Interesses e Ação Política: trajetória histórica e novas configurações. Revista de Sociologia e Política, v. 9, p. 101-139, 2010.

DUMÉNIL, Gerard; LEVY, Dominique. "O imperialismo na era neoliberal”. Crítica Marxista, n¹8, Rio de Janeiro, 2004, p.11-36.

ENGELS, Friedrich; MARX, Karl. A ideologia alemã. São Paulo: Boitempo, 2007.

GALVÃO, Andreia. A CUT na encruzilhada: dilemas do movimento sindical combativo. Idéias, Campinas, v. 09, 2003. 
HALL, Stuart. "Significação, Representação, Ideologia. Althusser e os debates pósestruturalistas" e "O PROBLEMA DA IDEOLOGIA. O Marxismo sem garantias" In: __ . Da diáspora. Identidades e mediações culturais. Belo Horizonte, Editora UFMG, 2003, p. 51-128.

HARVEY, David. O Neoliberalismo: história e implicações. Tradução: Adail Sobral e Maria Stela Gonçalves. São Paulo: Edições Loyola, 2008.

LENIN, Vladimir. O imperialismo: fase superior do capitalismo. São Paulo: Global, 1985.

MARTUSCELLI, Danilo. Crises políticas e capitalismo neoliberal no Brasil. 334 p. Tese (doutorado) Programa de Pós-Graduação em Ciência Política - Unicamp, Campinas, nov, 2013.

NAVES, Márcio. Presença de Althusser. Campinas: Unicamp, 2010, p.9-30.

NOGARA, Tiago Soares; OLIVEIRA, Thiago Prestes de. O MBR-200 e o enfrentamento prolongado ao neoliberalismo. REBELA - Revista Brasileira de Estudos LatinoAmericanos, v. 7, p. 53-75, 2017.

OLIVEIRA, Thiago. A Central Única dos Trabalhadores revisitada: análise dos congressos (1984-1991). Trabalho de Conclusão de Curso (Graduação em Ciências Sociais). UFRGS, Porto Alegre, jan, 2018.

OSTRY, Jonathan; LOUNGANI, Prakash; FURCERI, Davide. "Neoliberalism: Oversold? ". IMF Finance \& Development. Junho. 2016, Volume 53, No. 2. Disponível em: $<$ https:// www.imf.org/external/pubs/ft/fandd/2016/06/pdf/ostry.pdf>Acesso em: 20. Junho.2017.

SAAD FILHO, Alfredo. Neoliberalismo: uma análise marxista. In: Marx e o Marxismo, vol. 3 (4), jan./jun. 2015.

SALLUM Jr., Brasilio. O Brasil sob Cardoso: neoliberalismo e desenvolvimentismo. Tempo Social. Revista de Sociologia da USP, São Paulo, v. 11, n.2, p. 26-51, 1999.

SANTOS, Theotônio. Carta Aberta a Fernando Henrique Cardoso. Disponível em: $<\mathrm{http}$ //theotoniodossantos.blogspot.com.br/2010/10/carta-aberta-fernando-henriquecardoso.html>. Acesso em 25/02/2018.

SEGRILLO, Angelo. A Confusão Esquerda/Direita no Mundo Pós-Muro de Berlim: uma análise e uma hipótese. DADOS, Rio de Janeiro, v. 47, p. 615-632, 2004. 
